\title{
Martin G. Klingbeil, Yosef Garfinkel, Saar Ganor, Michael Hasel. Khirbet Qeiyafa Vol. 2. Excavation Report 2009-2013: Stratigraphy and Architecture (Areas B, C, D, E)
}

\section{Astrid Nunn}

\section{OpenEdition}

\section{Journals}

Édition électronique

URL : http://journals.openedition.org/abstractairanica/42606

DOI : 10.4000/abstractairanica.42606

ISBN : 1961-960X

ISSN : 1961-960X

Éditeur :

CNRS (UMR 7528 Mondes iraniens et indiens), Éditions de l'IFRI

\section{Référence électronique}

Astrid Nunn, « Martin G. Klingbeil, Yosef Garfinkel, Saar Ganor, Michael Hasel. Khirbet Qeiyafa Vol. 2. Excavation Report 2009-2013: Stratigraphy and Architecture (Areas B, C, D, E) », Abstracta Iranica [En ligne], Volume 37-38-39 | 2018, document 16, mis en ligne le 10 mars 2018, consulté le 28 septembre 2020. URL : http://journals.openedition.org/abstractairanica/42606 ; DOI : https://doi.org/10.4000/ abstractairanica.42606

Ce document a été généré automatiquement le 28 septembre 2020.

Tous droits réservés 
Martin G. Klingbeil, Yosef Garfinkel, Saar Ganor, Michael Hasel. Khirbet Qeiyafa Vol. 2. Excavation Report 2009-2013: Stratigraphy and Architecture (Areas B, C, D, E)

Astrid Nunn 


\section{RÉFÉRENCE}

Martin G. Klingbeil, Yosef Garfinkel, Saar Ganor, Michael Hasel. Khirbet Qeiyafa Vol. 2. Excavation Report 2009-2013: Stratigraphy and Architecture (Areas B, C, D, E).

Jerusalem, 2014, $704 \mathrm{p}$.

Le premier volume de la publication finale de Khirbet Qeiyafa, situé à $20 \mathrm{~km}$ au nord de Lachish, a paru en 2009 (cf. c.r. Yosef Garfinkel, Saar Ganor (éds.). Khirbet Qeiyafa, vol. 1. Excavation Report 2007-2008, Jerusalem, 2009). Les couches les plus épaisses sont pré- et post achéménides, mais celle de l'époque achéménide tardive est néanmoins assez impressionnante. Une enceinte et de nombreuses pièces appartenant à plusieurs bâtiments qui s'adossent à elle, ont été découvertes dans l'Area C (p. 100-128). Ce bel ensemble construit de pierre semble remonter au Fer, où il représentait des casemates qui furent réutilisées comme dépôts à partir de l'achéménide tardif. La porte de passage dans l'enceinte du Fer fut bloquée et remplacée plus tard par une autre porte dans l'Area C. Outre les pièces (Buildings C101-103) il existe un ensemble, le Building C100, qui comprend 20 unités, dont deux cours. Des structures semblables ont été révélées dans l'Area D (p. 231-235) et $\mathrm{E}$ (p. 310-313) également situés le long de l'enceinte mais respectivement au nord-ouest et à l'est de C. Quelques monnaies et cachets appartiennent au rare matériel achéménide.

\section{AUTEURS}

\section{ASTRID NUNN}

Université de Munich 